\title{
Changes of post-operative peripheral blood dendritic cells in patients undergoing laparoscopy
}

\author{
KAMIL TORRES ${ }^{l}$, ŁUKASZ PIETRZYK ${ }^{1}$, MARTA DENISOW-PIETRZYK ${ }^{1}$, SEBASTIAN RADEJ ${ }^{2}$, \\ ANDRZEJ CHROŚCICKI ${ }^{3}$, ANNA TORRES ${ }^{2}$ \\ ${ }^{1}$ Department of Didactics and Medical Simulation, Chair of Human Anatomy, Medical University of Lublin, Poland \\ ${ }^{2}$ Laboratory of Biostructure, Chair and Department of Human Anatomy, Medical University of Lublin, Poland \\ ${ }^{3}$ Department of General and Oncological Surgery, District Specialist Hospital of Lublin, Poland
}

\begin{abstract}
Introduction: Surgical intervention affects local and systemic immune responses, especially in obese individuals. Many studies have attempted to evaluate immunological response to surgical trauma. Surgery changes the quantity and phenotype of circulating blood dendritic cells (DCs), including a decrease of total DCs post-operatively. The study aimed to evaluate the percentage and changes of myeloid, lymphoid DCs, and myeloid to lymphoid DCs ratio in obese and normal weight patients undergoing laparoscopy.

Material and methods: The study enrolled asymptomatic patients with gallstones, who underwent laparoscopic cholecystectomy. Blood samples were obtained before the surgery as well as 24 and 48 hours after the surgery. Cells were collected using a FACSCalibur flow cytometry, and phenotypes were analyzed with CellQuest software.

Results: No statistically significant differences were observed between obese and normal-weighted patients in all studied time periods, except for the myeloid to lymphoid DCs ratio assessed at 48-post-operative hour. The myeloid DCs percentage increased significantly in the post-operative period within both studied groups. The percentage of lymphoid DCs increased significantly in obese patients in all studied time periods.

Conclusions: Laparoscopy induces immunomodulation, such as changes of myeloid and lymphoid dendritic cells, especially in obese patients. We describe new findings, in which minimally invasive surgical trauma promotes the increase of percentage of circulating DCs in the early post-operative period.
\end{abstract}

Key words: dendritic cells, obesity, laparoscopy, surgery, immune system.

(Cent Eur J Immunol 2020; 45 (3): 310-314)

\section{Introduction}

Obesity is increasing, global health problem [1]. An excessive amount of adipose tissue is a major risk factor for cardiovascular, metabolic, and musculoskeletal diseases as well as cancer. Moreover, the adipose tissue being endocrine active alters the inflammatory and immunological response [2, 3]. Recently, it was reported that surgical intervention affects local and systemic immune responses, particularly in obese individuals [4]. Laparoscopic technique, due to its minimal invasiveness, is considered to preserve immune function. Nevertheless, the immunological consequences of laparoscopic surgeries are still not entirely described $[5,6]$.
Dendritic cells (DCs) are the most potent antigen-presenting cells (APCs), which are able to initiate and regulate immunological responses [7]. There are at least two well-characterized subsets of circulating DCs: myeloid DCs (BDCA- ${ }^{+}$and CD19-) and lymphoid DCs (BDCA-2 ${ }^{+}$and $\mathrm{CD}_{123^{+}}$[ [8]. Many studies have attempted to evaluate immunological response to surgical trauma. Surgery changes the quantity and phenotype of circulating blood DCs, including a decrease of total DCs post-operatively [9-11].

The present study aimed to evaluate the percentage and changes of the myeloid (BDCA- ${ }^{+}$and CD19-), lymphoid $\left(\mathrm{BDCA}-2^{+}\right.$and $\mathrm{CD} 123^{+}$) cells, and the myeloid to lymphoid cells ratio (BDCA- $1^{+}$and $\mathrm{CD} 19^{-} / \mathrm{BDCA}-2^{+}$and $\left.\mathrm{CD} 123^{+}\right)$in obese and normal weight patients undergoing laparoscopy.

Correspondence: Kamil Torres MD, PhD, Department of Didactics and Medical Simulation, Chair of Human Anatomy, Medical University of Lublin, 4 Jaczewskiego St., 20-094 Lublin, Poland, e-mail: kamiltorres@wp.pl Submitted: 17.01.2018; Accepted: 1.02.2018 


\section{Material and methods}

\section{Study population}

The study enrolled patients with cholelithiasis admitted to the General and Oncological Surgery Department of the District Specialist Hospital of Lublin, Poland. The study group consisted of 60 asymptomatic patients with gallstones shown by ultrasound examination. Patients with ultrasounds' signs of gallbladder complications (e.g., empyema, hydrops, wall necrosis, jaundice, and other), symptoms of acute cholecystitis, and a history of diabetes and immunologic disorders or allergies were excluded.

All the patients underwent laparoscopic cholecystectomy with standard values of carbon dioxide pneumoperitoneum (12-14 mm $\mathrm{Hg}$ ). The patients underwent surgery performed via a four-trocar technique. After recognition of Calot's triangle, the cystic duct and cystic artery were clipped and cut. Gallbladder was removed with a medical protector through an incision below the umbilicus. In each case, the gallbladder was evaluated by pathologic examination, and no malignancy was observed. No complications during the early post-operative period were reported. All the patients were informed about the aims of the study, and a written consent was obtained from each patient. The study was approved by the Ethical Committee at the Medical University of Lublin (decision No. KE-0254/240/2008).

Patients were divided into two groups according to body mass index (BMI): group $\mathrm{N}\left(n=29, \mathrm{BMI} \leq 25 \mathrm{~kg} / \mathrm{m}^{2}\right)$ and group $\mathrm{O}\left(n=31, \mathrm{BMI}>30 \mathrm{~kg} / \mathrm{m}^{2}\right)$.

\section{Blood collection, preparation, and flow cytometric evaluation}

Blood samples were obtained before the surgery as well as 24 and 48 hours after the procedure. Mononuclear cells were separated on lymphocyte separation medium - Gradisol L (Aqua Med, Poland) and centrifuged for 20 minutes at $700 \times \mathrm{g}$. Every $10^{7}$ of mononuclear cells were incubated with $10 \mu \mathrm{l}$ of FcR - blocking reagent (Miltenyi Biotec, Germany) for 5 minutes to avoid non-specific binding and labeled with monoclonal antibodies against following antigens: BDCA-1, BDCA-2, and CD19. After incubation, cells were centrifuged and washed for 5 minutes at 700 $\times \mathrm{g}$ in 4 degrees of Celsius. The myeloid dendritic cells: anti - BDCA-1 (CD1c) FITC (Miltenyi Biotec, Germany) and anti - CD19 CyChrome (Becton Dickinson, USA). The lymphoid dendritic cells: anti - BDCA-2 (Miltenyi Biotec, Germany) and CD123 PE (Becton Dickinson, USA). The cells were collected using a FACSCalibur flow cytometry (Becton Dickinson, USA) and the phenotypes were analyzed with CellQuest software (Becton Dickinson, USA). For each analysis, 300,000 of events were collected. Cell debris and dead cells were excluded based on scatter signal. The fluorescence-minus-one method or the unstained cell were applied as negative control.

\section{Statistical analysis}

Statistical analysis was performed using 16.0 SPSS software (SPSS, Chicago, IL, USA). Differences between studied patients' populations were assessed using the Mann-Whitney U test. Differences from baseline within each group were evaluated with the Wilcoxon matchedpairs signed-ranks test. All p-values lower than 0.05 were considered significant.

\section{Results \\ Patients population}

The patients were assigned into two study groups. Group $\mathrm{N}$ consisted of 29 patients ( $\mathrm{M}: \mathrm{F}$ ratio $=15: 14)$, while group $\mathrm{O}$ included 31 patients $(\mathrm{M}: \mathrm{F}$ ratio $=16: 15)$. The median age of patients was 53 and 55 years, respectively, in group $\mathrm{N}$ and $\mathrm{O}$. The groups differed significantly $(p<0.001)$ in terms of BMI. In group N, BMI was $23.15 \mathrm{~kg} / \mathrm{m}^{2}$ (range, $18.45-24.73 \mathrm{~kg} / \mathrm{m}^{2}$ ) and in group $\mathrm{O}$, it was $31.35 \mathrm{~kg} / \mathrm{m}^{2}$ (range, $30.02-39.40 \mathrm{~kg} / \mathrm{m}^{2}$ ). There were no statistically significant differences between the two study groups in terms of duration of the surgery (45.40 min in group $\mathrm{N}$ and $51.02 \mathrm{~min}$ in group $\mathrm{O}$ ), and hematological and biochemical parameters assessed before and after the surgery. The median body temperature, white blood counts (WBC), and C-reactive protein (CRP) were similar in both study groups post-operatively. No complications (e.g., fever, wound infection) were observed during post-operative period in all studied patients.

\section{Circulating DCs subsets in obese and normal- weighted patients before and after the surgery}

The percentage of myeloid (BDCA- $1^{+}$and $\mathrm{CD} 19^{-}$), lymphoid (BDCA-2 $2^{+}$and $\mathrm{CD} 123^{+}$) cells, and the myeloid to lymphoid cells ratio (BDCA- ${ }^{+}$and CD19-/BDCA-2 ${ }^{+}$ and $\mathrm{CD} 123^{+}$) was analyzed in three times points in both study groups. There were no statistically significant differences between obese and normal-weighted patients before (pre-OP), and at 24 and 48 hours after the surgery, except the myeloid to lymphoid cells ratio (BDCA- $1^{+}$and CD19-/ BDCA- $2^{+}$and $\mathrm{CD}_{123^{+}}$) assessed in the 48-post-operative hour. The results are presented in Table 1.

\section{Post-operative changes of circulating DCs subsets}

The percentage of myeloid (BDCA- $1^{+}$and CD19-), lymphoid (BDCA- $2^{+}$and $\mathrm{CD}_{123^{+}}$) cells as well as the myeloid to lymphoid cells ratio (BDCA- $1^{+}$and CD19-/BDCA-2 ${ }^{+}$ and $\mathrm{CD} 123^{+}$) was determined in three time periods (Table 2). In group $\mathrm{N}$ and $\mathrm{O}$, we did not observe significant changes in the percentage of the myeloid DCs at post-OP $24 \mathrm{~h}$ compared to pre-OP baseline level. However, the myeloid DCs percentage increased significantly at post- 
Table 1. Percentages of myeloid (BDCA- $1^{+}$and CD19-) and lymphoid (BDCA-2 ${ }^{+}$and $\mathrm{CD} 123^{+}$) cells, and the myeloid to lymphoid cells ratio (BDCA $-1^{+}$and $\mathrm{CD} 19^{-} / \mathrm{BDCA}-2^{+}$and $\mathrm{CD} 123^{+}$) in peripheral blood of patients in both studied groups at three time points

\begin{tabular}{|c|c|c|c|c|c|}
\hline \multirow[t]{3}{*}{ Parameter } & \multicolumn{4}{|c|}{ Group } & \multirow[t]{3}{*}{$p$-value } \\
\hline & \multicolumn{2}{|c|}{$\mathbf{N}$} & \multicolumn{2}{|c|}{$\mathbf{O}$} & \\
\hline & Median (\%) & $\operatorname{Min}-\max (\%)$ & Median (\%) & $\operatorname{Min}-\max (\%)$ & \\
\hline $\mathrm{BDCA}-1^{+} / \mathrm{CD} 19^{-}$pre-OP & 0.18 & $0.02-0.31$ & 0.17 & $0.09-0.35$ & 0.484 \\
\hline $\mathrm{BDCA}-1^{+} / \mathrm{CD} 19^{-}$post-OP $24 \mathrm{~h}$ & 0.20 & $0.01-0.40$ & 0.20 & $0.06-0.33$ & 0.969 \\
\hline BDCA-1+/CD19- post-OP $48 \mathrm{~h}$ & 0.22 & $0.07-0.49$ & 0.24 & $0.12-0.43$ & 0.388 \\
\hline $\mathrm{BDCA}-2^{+} / \mathrm{CD} 123^{+}$pre-OP & 0.16 & $0.02-0.27$ & 0.16 & $0.05-0.33$ & 0.761 \\
\hline $\mathrm{BDCA}-2^{+} / \mathrm{CD} 123^{+}$post-OP $24 \mathrm{~h}$ & 0.19 & $0.06-0.31$ & 0.22 & $0.05-0.41$ & 0.421 \\
\hline $\mathrm{BDCA}-2^{+} / \mathrm{CD} 123^{+}$post-OP $48 \mathrm{~h}$ & 0.17 & $0.08-0.37$ & 0.27 & $0.09-0.54$ & 0.171 \\
\hline BDCA-1 $1^{+} / \mathrm{CD} 19^{-} / \mathrm{BDCA}^{-} 2^{+} / \mathrm{CD} 123^{+}$pre-OP & 1.20 & $0.67-2.42$ & 1.18 & $0.45-4.78$ & 0.968 \\
\hline BDCA-1 $1^{+} / \mathrm{CD} 19^{-} / \mathrm{BDCA}-2^{+} / \mathrm{CD} 123^{+}$post-OP $24 \mathrm{~h}$ & 1.14 & $0.14-1.91$ & 0.98 & $0.38-2.53$ & 0.280 \\
\hline $\mathrm{BDCA}-1^{+} / \mathrm{CD} 19^{-} / \mathrm{BDCA}-2^{+} / \mathrm{CD} 123^{+}$post-OP $48 \mathrm{~h}$ & 1.27 & $0.62-2.41$ & 1.00 & $0.41-2.71$ & 0.031 \\
\hline
\end{tabular}

Table 2. Changes of the percentage of myeloid (BDCA- $1^{+}$ and $\mathrm{CD} 19^{-}$) and lymphoid (BDCA-2 ${ }^{+}$and $\mathrm{CD} 123^{+}$) cells, and the myeloid to lymphoid cells ratio (BDCA- $1^{+}$and CD19-/BDCA-2 ${ }^{+}$and $\mathrm{CD}^{-} 23^{+}$) in peripheral blood of patients in both studied groups at three time periods

\begin{tabular}{|c|c|c|}
\hline \multirow[t]{2}{*}{ Parameter } & \multicolumn{2}{|c|}{ Group } \\
\hline & $\mathbf{N}$ & $\mathbf{O}$ \\
\hline BDCA- $1^{+} / \mathrm{CD} 19^{-}$time period $0-24 \mathrm{~h}$ & $\leftrightarrow(5.27 \%)$ & $\leftrightarrow(10.51 \%)$ \\
\hline BDCA-1 ${ }^{+} / \mathrm{CD} 19^{-}$time period $24-48 \mathrm{~h}$ & $\uparrow(14.79 \%)$ & $\uparrow(28.10 \%)$ \\
\hline BDCA- $1^{+} / \mathrm{CD} 19^{-}$time period $0-48 \mathrm{~h}$ & $\uparrow(19.98 \%)$ & $\uparrow(33.31 \%)$ \\
\hline $\mathrm{BDCA}-2^{+} / \mathrm{CD} 123^{+}$time period $0-24 \mathrm{~h}$ & $\uparrow(15.36 \%)$ & $\uparrow(26.30 \%)$ \\
\hline $\mathrm{BDCA}-2^{+} / \mathrm{CD} 123^{+}$time period $24-48 \mathrm{~h}$ & $\leftrightarrow(-9.50 \%) *$ & $\uparrow(18.40 \%)^{*}$ \\
\hline $\mathrm{BDCA}-2^{+} / \mathrm{CD} 123^{+}$time period $0-48 \mathrm{~h}$ & $\leftrightarrow(5.54 \%)^{*}$ & $\uparrow(47.60 \%)^{*}$ \\
\hline $\begin{array}{l}\text { BDCA- } 1^{+} / \mathrm{CD} 19-/ \mathrm{BDCA}-2^{+} / \mathrm{CD} 123^{+} \\
\text {time period } 0-24 \mathrm{~h}\end{array}$ & $\leftrightarrow(-4.90 \%)$ & $\downarrow(-5.04 \%)$ \\
\hline $\begin{array}{l}\text { BDCA- } 1^{+} / \mathrm{CD} 19-/ \mathrm{BDCA}-2^{+} / \mathrm{CD} 123^{+} \\
\text {time period } 24-48 \mathrm{~h}\end{array}$ & $\uparrow(12.77 \%)$ & $\leftrightarrow(4.91 \%)$ \\
\hline $\begin{array}{l}\mathrm{BDCA}-1^{+} / \mathrm{CD} 19^{-} / \mathrm{BDCA}^{-} 2^{+} / \mathrm{CD} 123^{+} \\
\text {time period } 0-48 \mathrm{~h}\end{array}$ & $\leftrightarrow(4.90 \%)$ & $\leftrightarrow(-4.44 \%)$ \\
\hline
\end{tabular}

$\overline{\uparrow \text { statistically significant increase, } \downarrow \text { statistically significant decrease, } \leftrightarrow \text { no }}$ statistically significant change, * statistically significant change in group O compared to group $N$

OP $48 \mathrm{~h}$ compared to post-OP $24 \mathrm{~h}$ and pre-OP baseline in both studied groups. The percentage of lymphoid DCs increased significantly in group $\mathrm{O}$ in all studied time periods, while in group $\mathrm{N}$, the only one significant change was observed at post-OP $24 \mathrm{~h}$ compared to pre-OP baseline level. In group N, the myeloid DCs to lymphoid DCs ratio significantly increased at post-OP $48 \mathrm{~h}$ compared to postOP $24 \mathrm{~h}$. In group O, the myeloid DCs to lymphoid DCs ratio increased significantly at post-OP $24 \mathrm{~h}$ compared to pre-OP baseline levels.

\section{Discussion}

Nowadays, minimally invasive surgical techniques have become a standard in the treatment of numerous diseases affecting almost all body system [12]. Even though laparoscopy is considered to reduce tissue damage when compared to open surgery, it is still followed by activation of immune system at both local and systemic levels $[5,6]$. The response to surgery could be impaired in obese individuals $[2,4]$. Adipose tissue is recognized as a significant endocrine organ [13]. It houses inflammatory cells and secretes active mediators of inflammation, including adiponectin, leptin, interleukin 6 (IL-6), and tumor necrosis factor-a (TNF-a) [3, 14].

Our investigation did not show significant differences in the percentage of the myeloid (BDCA- $1^{+}$and $\mathrm{CD} 19^{-}$), lymphoid (BDCA-2+ ${ }^{+}$and $\mathrm{CD} 123^{+}$) cells, and the myeloid to lymphoid cells ratio (BDCA- $1^{+}$and $\mathrm{CD} 19^{-} / \mathrm{BDCA}^{-2}{ }^{+}$ and $\mathrm{CD} 123^{+}$) before and after the surgery in obese compared to normal-weight patients. To date, researches have not been focusing on the evaluation of DCs' populations in human adipose tissue. However, several studies have described the effects of adipocyte and adipocyte-derived factors on myeloid cells, and have identified and phenotype different subsets of DCs in human subcutaneous adipose tissue, which could not be translated to visceral adipose tissue [15-17]. Based on murine models, authors suggested a role of DCs, particularly conventional DCs, in the promotion of low-grade inflammation in adipose tissue [18]. Despite compelling evidence, the role of DCs in the adipose tissue remains unclear and requires further investigations. The percentage of myeloid and lymphoid DCs in 
the peripheral blood was evaluated by Nickel et al. [19]. Authors described the lower expression of myeloid DCs in obese compared to lean individuals, while the percentage of lymphoid DCs was in opposite: it was higher in obese than in normal weight persons. Differences in expression of circulating myeloid and lymphoid DCs in normal weight and obese individuals suggest that excessive amount of adipose tissue modifies the immune system. However, the exact mechanism and direction of this modulation are not fully understood.

We observed a significant increase of the percentage of myeloid (BDCA- $1^{+}$and CD19-) DCs in the early post-operative period in both study groups. However, the tendency to higher increase of DCs' percentage was typical for obese patients. The percentage of lymphoid DCs $\left(\mathrm{BDCA}-2^{+}\right.$and $\mathrm{CD} 123^{+}$) increased significantly in the early post-operative period in obese compared to normal weight patients. However, in the first 24 post-operative hours, an increase of lymphoid DCs was also observed in normal weigh patients. Lymphoid DCs are considered to display a dual function of Ag-capturing and potent inhibition of IFN- $\alpha / \beta$ induction [20]. The significant increase of lymphoid DCs might cause skewing $\mathrm{T}$ cell responses towards a non-Th1 type of response and therefore, decrease of Th1 polarization and weaker response to intracellular pathogens [21, 22]. Our results are in contrast with the study of Ho et al., who monitored changes in DCs counts in patients undergoing laparoscopic cholecystectomy [23]. They observed a significant increase of DCs count intraoperatively compared to the level before the surgery; however, in the post-operative period, the DCs counts significantly decreased.

The myeloid to lymphoid DCs ratio $\left(\mathrm{BDCA}-1^{+}\right.$and CD19-/BDCA-2 $2^{+}$and $\mathrm{CD}_{123^{+}}$) in the peripheral blood might revealed the imbalance of $\mathrm{Th} 1$ and $\mathrm{Th} 2$ polarization $[20,21]$. After surgery, higher myeloid to lymphoid DCs ratio can suggest Th1 polarization, activation of cytotoxic cells, and leads to tissue damage and formation of intraperitoneal adhesions. By contrast, low post-operative myeloid to lymphoid DCs ratio favor humoral response and promotes elimination of bacterial infections and development of immunological tolerance.

In our study, we did not observe significant differences in the myeloid to lymphoid DCs ratio between study groups. In the first 24 post-operative hours, the myeloid to lymphoid DCs ratio significantly decreased in obese patients. It suggests a stronger activation of lymphoid than myeloid DCs due to surgical trauma.

\section{Conclusions}

Laparoscopy induces immunomodulation, such as changes of myeloid and lymphoid dendritic cells, especially in obese patients. We describe new findings, in which minimally invasive surgical trauma promotes the increase of percentage of circulating DCs in the early post-operative period. Future studies are required to greatly investigate the role of an excessive amount of adipose tissue on peripheral blood DCs and immune response in patients undergoing surgeries.

\section{Acknowledgement}

The study was supported by the Medical University of Lublin, Poland (grant No. DS205).

\section{The authors declare no conflict of interest.}

\section{References}

1. Fruh SM (2017): Obesity: Risk factors, complications, and strategies for sustainable long-term weight management. J Am Assoc Nurse Pract 29: 3-14.

2. Cefalu WT, Bray GA, Home PD, et al. (2015): Advances in the Science, Treatment, and Prevention of the Disease of Obesity: Reflections From a Diabetes Care Editors' Expert Forum. Diabetes Care 38: 1567-1582.

3. Pietrzyk L, Torres A, Maciejewski R, Torres K (2015): Obesity and Obese-related Chronic Low-grade Inflammation in Promotion of Colorectal Cancer Development. Asian Pac J Cancer Prev 16: 4161-4168.

4. Kuhry E, Jeekel J, Bonjer HJ (2004): Effect of laparoscopy on the immune system. Semin Laparosc Surg 11: 37-44.

5. Wu HY, Li F, Tang QF (2010): Immunological effects of laparoscopic and open cholecystectomy. J Int Med Res 38: 2077-2083.

6. Torres K, Torres A, Chrościcki A, et al. (2013): Evaluation of lymphocytes $\mathrm{CD}^{+}$and $\mathrm{CD} 8^{+}$and expression of ZAP-70 kinase on $\mathrm{CD}^{+}$and $\mathrm{CD} 19^{+}$lymphocytes in obese patients undergoing laparoscopic cholecystectomy. Surg Endosc 27: 872-879.

7. McKenna K, Beignon A-S, Bhardwaj N (2005): Plasmacytoid dendritic cells: linking innate and adaptive immunity. J Virol 79: 17-27.

8. Narbutt J, Lesiak A, Zak-Prelich M, et al. (2004): The distribution of peripheral blood dendritic cells assayed by a new panel of anti- BDCA monoclonal antibodies in healthy representatives of the polish population. Cell Mol Biol Lett 9: 497-509.

9. Wang D, Yang XL, Chai XQ, et al. (2016): A short-term increase of the postoperative naturally circulating dendritic cells subsets in flurbiprofen-treated patients with esophageal carcinoma undergoing thoracic surgery. Oncotarget 7: 1870518712.

10. Li H, Wang C, Yu J, et al. (2009): Dendritic cell-activated cytokine-induced killer cells enhance the anti-tumor effect of chemotherapy on non-small cell lung cancer in patients after surgery. Cytotherapy 11: 1076-1083.

11. McAuliffe PF, Efron PA, Scumpia PO, et al. (2005): Varying blood monocyte and dendritic cell responses after laparoscopic versus open gastric bypass surgery. Obes Surg 15: 1424-1431.

12. Antoniou SA, Antoniou GA, Antoniou AI, Granderath FA (2015): Past, Present, and Future of Minimally Invasive Abdominal Surgery. JSLS 19: e2015.00052. 
13. Galic S, Oakhill JS, Steinberg GR (2010): Adipose tissue as an endocrine organ. Mol Cell Endocrinol 316: 129-139.

14. Sundara Rajan S, Longhi MP (2016): Dendritic cells and adipose tissue. Immunology 149: 353-361.

15. Lumeng CN, Bodzin JL, Saltiel AR (2007): Obesity induces a phenotypic switch in adipose tissue macrophage polarization. J Clin Invest 117: 175-184.

16. Gonzalez-Rey E, Anderson P, Gonzalez MA, et al. (2009): Human adult stem cells derived from adipose tissue protect against experimental colitis and sepsis. Gut 58: 929-939.

17. Bertola A, Ciucci T, Rousseau D, et al. (2012): Identification of adipose tissue dendritic cells correlated with obesity-associated insulin-resistance and inducing Th17 responses in mice and patients. Diabetes 61: 2238-2247.

18. Majdoubi A, Kishta OA, Thibodeau J (2016): Role of antigen presentation in the production of pro-inflammatory cytokines in obese adipose tissue. Cytokine 82: 112-121.

19. Nickel T, Hanssen H, Emslander I, et al. (2011): Immunomodulatory effects of aerobic training in obesity. Mediators Inflamm 2011: 308965.

20. Dzionek A, Sohma Y, Nagafune J, et al. (2001): BDCA-2, a novel plasmacytoid dendritic cell-specific type II C-type lectin, mediates antigen capture and is a potent inhibitor of interferon alpha/beta induction. J Exp Med 194: 1823-1834.

21. Cella M, Facchetti F, Lanzavecchia A, Colonna M (2000): Plasmacytoid dendritic cells activated by influenza virus and CD40L drive a potent TH1 polarization. Nat Immunol 1: 305310.

22. Kadowaki N, Antonenko S, Lau JY, Liu YJ (2000): Natural interferon alpha/beta-producing cells link innate and adaptive immunity. J Exp Med 192: 219-226.

23. Ho CS, López JA, Vuckovic S, et al. (2001): Surgical and physical stress increases circulating blood dendritic cell counts independently of monocyte counts. Blood 98: 140-145. 